\title{
Predication and Equation
}

\author{
David Adger and Gillian Ramchand
}

August 9, 2001

\section{Introduction: Predication and the Syntax-Semantics Interface}

Natural language propositions are often considered to contain a thematic core expressing predicate argument relationships (often termed a small clause). Work exploring this idea has been foundational, both to our understanding of clause structure (Williams 1980, Williams 1983a, Manzini 1983, Hoekstra 1984, Bowers 1993, Stowell 1981 and many others) and the semantic construction of predicational relationships (Higginbotham 1985, Rothstein 1995, Doron 1983, Rapoport 1987, among others). This paper defends the view that there is an extremely tight relationship between the syntax and semantics of predication, and that semantic predication always feeds off a syntactic structure containing a predicational head (following Bowers 1993; Svenonius 1994). We do this on the basis of data from Scottish Gaelic, which appears to challenge such a tightly constrained relationship between syntax and semantics. We show that this data, when understood properly, actually provides extra motivation for this approach. This means that it is not necessary to postulate different types of underlying structure to account for apparent differences in the interpretation of predication (contra Rothstein 1995, Rapoport 1987, Pereltsvaig 2001).

More specifically, the view that we defend is that a clause consists of a predicational core where thematic relations are licensed, and which is delimited by a head, Pred. Pred acts as the syntactic edge of the predicational core (Chomsky 1998, Chomsky 1999) and its projection is surmounted by an articulated functional domain containing heads which check formal features, trigger displacement, and mediate other important grammatical and information structural properties of the clause. The predicational core itself is asymmetrically constituted such that the 'argument' of the predicate constructed by the head and its complement sits in the specifier position of the predicate phrase.

(1)

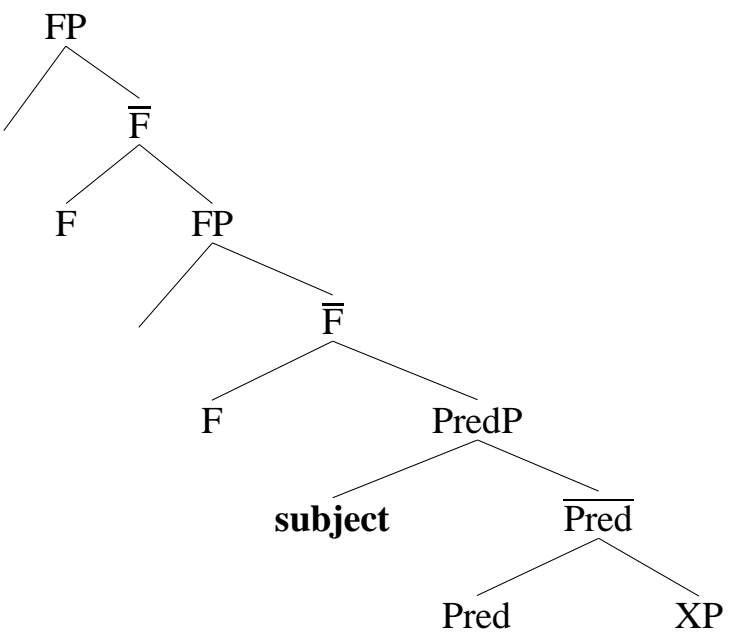


This kind of view of the lower domain of clause structure developed from early work by Stowell (1981) which took lexical categories themselves to be predicational. Once it is assumed that predication is mediated through an (essentially) functional head (see, for example, Hornstein and Lightfoot 1987, Raposo and Uriagereka 1990, Moro 1988), the question arises as to what may be the complement of this head. More specifically, are there constraints upon the category, or the semantic type, of XP? A natural translation of Stowell's original insight into the current framework answers this question with a yes: the syntactic category of XP is restricted to the set of lexical categories (N, V, A, P) and semantically these categories may all be unsaturated, in the Fregean sense (see Higginbotham 1985).

The most pressing empirical challenge then becomes equative sentences. Equatives consist of two DPs and a copular verb:

\section{(2) Mairead's songs are Micheal's joy}

Since DPs are not lexical categories, and since at least some DPs are usually assumed to be saturated (Higginbotham 1985; Higginbotham 1987), it appears that we have a type of sentence which cannot be reduced to the predicational structure outlined above.

One way of dealing with this problem, is to site the source of the two kinds of predication in the copular verb $b e$. This entails that the copula is ambiguous, appearing as both a semantically empty auxiliary, and as a true verb signifying identity between its arguments (Higgins 1973, Rapoport 1987, Zaring 1996, Carnie 1997, Higginbotham 1987). From this perspective, (1) has a reading familiar from classical logic, where the identity predicate is introduced by the copula:

\section{(3) Mairead's-songs = Micheal's-joy}

Closely related to this idea are analyses where there are two different types of small clause, one underlying equative sentences, and the other underlying predicative sentences (Heycock 1994, Carnie 1997, Heycock and Kroch 1999), each with an associated logical representation. This idea divorces the kind of predication from the copula itself, thus avoiding having to specify an ambiguous copula. However, it weakens the tight one-to-one mapping between the syntax and semantics of predication represented by (1) above.

An alternative is to reject the assumption that proper names and other DPs such as possessives and definites are obligatorily saturated. This approach has been taken by Heggie (1988), Moro (1997) and, for pseudo-clefts, Williams (1994). These authors argue that, in cases where two DPs appear in copular sentences, one of them is semantically and syntactically the predicate, while the other is referential:

(4) (a) Jenny is the doctor.

(b) The doctor is Jenny.

Under this view, the doctor is the predicate in both these examples. Syntactically, the (b) example involves raising this DP predicate to some higher position ([Spec, CP] for Heggie (1988), [Spec, IP] for Moro (1997)). Heggie and Moro provide syntactic evidence (from extraction, cliticisation, pronominalisation, focus effects etc ) that there is a syntactic asymmetry in these cases. This kind of analysis entails either that we give up the PredP framework, or that somehow DPs may be the complement of Pred.

Assuming that we maintain the PredP framework, and that Pred always takes an unsaturated complement, we are forced to assume a more complicated picture of the relationship between the syntax and semantics of nominal projections. We have to allow DPs to have more than one interpretation, since they can be referential but also apparently predicative (Partee 1987). If DPs can be both predicative and referential then we do not have an obvious way of maintaining a strict one-to-one mapping between the syntactic category and the semantic type. 
Summarizing then, there are two broad lines of attack on the problem of how to approach sentences which contain two DPs: (i) adopt the idea that there are two kinds of predicational structure available, correlating roughly with predicational and equative interpretations; (ii) take the perspective that there is only one kind of predicational structure, but that the complement of Pred is not restricted to lexical categories.

English is one language where equative sentences and non-equative sentences have a similar surface syntax (but see Heggie 1988 and Moro 1997 for a discussion of more subtle differences). In this paper we address the fact that many other languages appear to use radically different morphological means which seem to map to intuitive differences in the type of predication expressed. We take one such language, Scottish Gaelic, and show that the real difference is not between equative and non-equative sentences, but is rather dependent on whether the predicational head in the structure proposed above is eventive or not.

We show that the aparently odd syntax of "equatives" in this language derives from the fact that they are constructed via a non-eventive Pred head. Since Pred heads cannot combine with non-predicative categories, such as saturated DPs, "equatives" are built up indirectly from a simple predicational structure with a semantically bleached predicate. This approach not only allows us to maintain a strict one-to-one syntax/semantics mapping for predicational syntax, but also for the syntax of DPs. The argument we develop here, then, suggests that the interface between the syntactic and semantic components is maximally economical — one could say perfect.

\section{Scottish Gaelic Predicational Structures}

One of the major arguments we present in this paper is that DPs cannot be the complement of Pred, a fact, which if true, receives an explanation based on the function of the D-layer in a DP and the syntactic requirements of Pred. We begin by outlining the syntax of clauses, and specifically predicative clauses in Scottish Gaelic with a view to establishing this claim.

\subsection{Basic clause structure}

Scottish Gaelic is a language closely related to Modern Irish. It has a basic VSO structure, with the finite verb preceding the subject and object. The arguments adduced by McCloskey (1983) to show that Modern Irish VSO is derived from an underlying SVO order can be replicated for Scottish Gaelic (Adger 1996, Ramchand 1997). We assume, therefore, that an example like the following has the structure indicated, with the verb raising from its base position to some head within the functional domain of the clause.

(5) Chunnaic $_{i}$ Calum [ $t_{i}$ Mairi].

See-PAST Calum Mairi

'Calum saw Mairi.'

The difference between Scottish Gaelic and more familiar SVO languages is just that in Scottish Gaelic, the main verb raises to $T$ while the the subject phrase remains in situ. Chung and McCloskey (1987) provide a compelling range of arguments which show that in Irish, when the verb does not raise (because T is absent, or filled with an auxiliary), the string containing the in situ subject and predicate behaves like a constituent. Once again, the same arguments can be made for Scottish Gaelic (Ramchand 1997).

This general picture of Irish and Scottish Gaelic clause structure is uncontroversial. For concreteness, however, we will translate these basic ideas and intuitions into a broadly Minimalist framework, following the notation and some of the ideas of Pesetsky and Torrego (2000), Chomsky (1999) and Chomsky (1998).

The approach to clausal structure we will follow is roughly that of Adger (2001). We adopt the idea that the VP domain is split into more than one head position (Larson 1987; Chomsky 1995b), and that the subject is Merged in the specifier of a 'little v', which is a particular flavour of Pred. 
We assume that heads and phrases consist of syntactic features, some of which are specified as uninterpretable. Uninterpretable features must be marked for deletion during the derivation, since they are not tolerated by the interface systems of Spellout or LF-Interpretation. We notate a feature $[\mathrm{F}]$ as uninterpretable by prefixing it with a $u$ : $[u \mathrm{~F}]$, following Pesetsky and Torrego (2000).

In addition to interpretability, features may also have an EPP property. The EPP property of a feature $\left[\mathrm{F}_{E P P}\right]$ is satisfied by filling the specifier of the head which $[\mathrm{F}]$ sits on $(\mathrm{H}(\mathrm{F}))$ with some XP with which F has Agreed, where the XP contains phonological material. This means that we adopt a view of the EPP which sees it as a structural licensing requirement for particular heads which feeds into well-formedness requirements of the spellout component. In some ways, EPP on a head is like an affixal-feature.

As far as head movement is concerned, we assume that if XP is the complement of $\mathrm{H}(\mathrm{F})$, then the head of $\mathrm{XP}(\mathrm{H}(\mathrm{XP})=\mathrm{X})$ moves and adjoins to $\mathrm{H}(\mathrm{F})$. Once again, we assume that the satisfaction of EPP is sensitive to phonology, making EPP which attracts heads even more like a stray-affix requirement.

To implement the generalisation that some overt material always appears in $\mathrm{T}$, we assume that $\mathrm{T}$ bears an EPP feature as a sub-feature of its category feature $\left[\mathrm{T}_{E P P}\right]$ (following Pesetsky and Torrego 2000). We follow Alexiadou and Anagnostopoulou (1998), who propose that languages differ in whether the EPP feature of $\mathrm{T}$ is satisfied by movement to $\mathrm{T}^{0}$ or $[\mathrm{Spec}, \mathrm{TP}]$, and assume that the parameter is set for $\mathrm{T}^{0}$ in Scottish Gaelic.

In Scottish Gaelic, the EPP feature of $T$ can actually be satisfied in one of two ways. The first way involves movement of the main verb from $\mathrm{V}$ through $\mathrm{v}$ and up to $\mathrm{T}$ (as in $(6,7)){ }^{1}$

(6) Dh'òl Calum an t-uisge beatha.

Drink-PAST Calum the whiskey

'Calum drank the whiskey.'

(7)

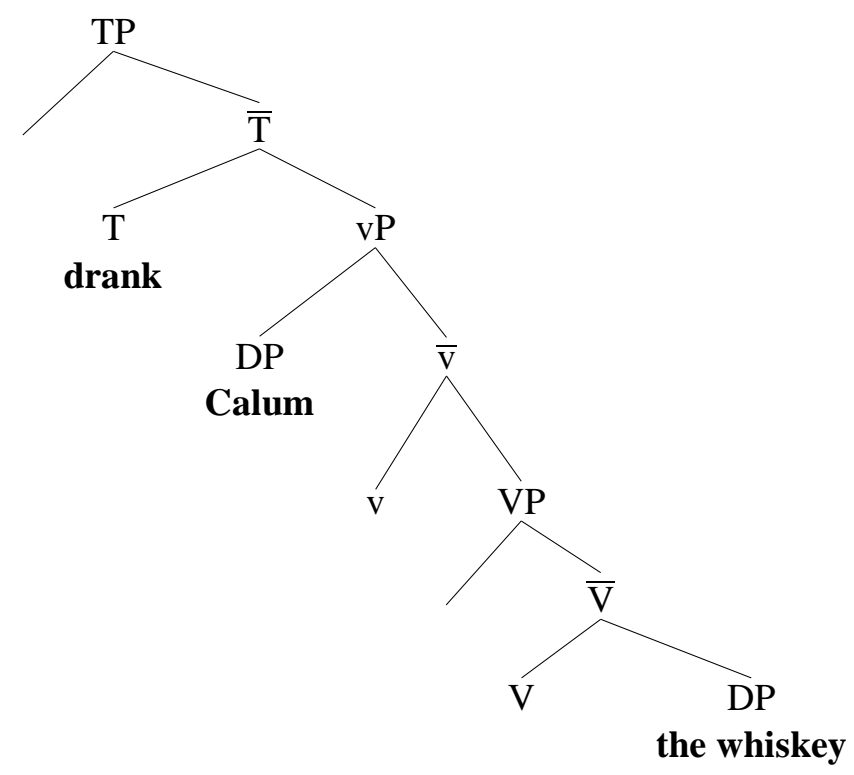

The second way to satisfy the EPP feature of $\mathrm{T}$ involves the Merge of an independent lexical item carrying pure tense features; compare (6) above with (8).

(8) Bha Calum ag òl uisge beatha.

Be-PAST Calum ASP drinking whiskey

'Calum was drinking whiskey.'

\footnotetext{
${ }^{1}$ This movement is mediated by the relation of Agree and is driven by the existence of uninterpretable $\mathrm{v}$ and $\mathrm{T}$ features on $\mathrm{V}$ and v respectively. See Adger (2001) for the details of the implementation in the Scottish Gaelic case.
} 
In this example $\mathrm{T}$ is filled by the finite auxiliary shown in the example above, which is usually a form of the verb bith, 'be'. Bith is, in the traditional grammatical literature, termed the substantive auxiliary and we will accordingly refer to these constructions as Substantive Auxiliary Constructions (SACs). The SAC allows us to see more clearly the range of constituents which can appear in the PredP position of the sentence. We demonstrate some of these possibilities in the following examples ${ }^{2}$ :

(9) Tha Calum faiceallach.

Be-PRES Calum careful

'Calum is (being) careful.'

(10) Tha Calum anns a'bhuth.

Be-PRES Calum in the shop

'Calum is in the shop.'

In the above examples, we see an AP predicate and a PP in the predicate position. We will assume that the subjects of these predicates are introduced by another variety of a little $\mathrm{v}$ head, which we will notate as Pred (Bowers 1993, Svenonius 1994, Adger 2001). Pred contains only interpretable features and so does not enter into an Agree relation with T. The EPP property of T's tense features is satisfied by Merging in a version of the substantive auxiliary bith.

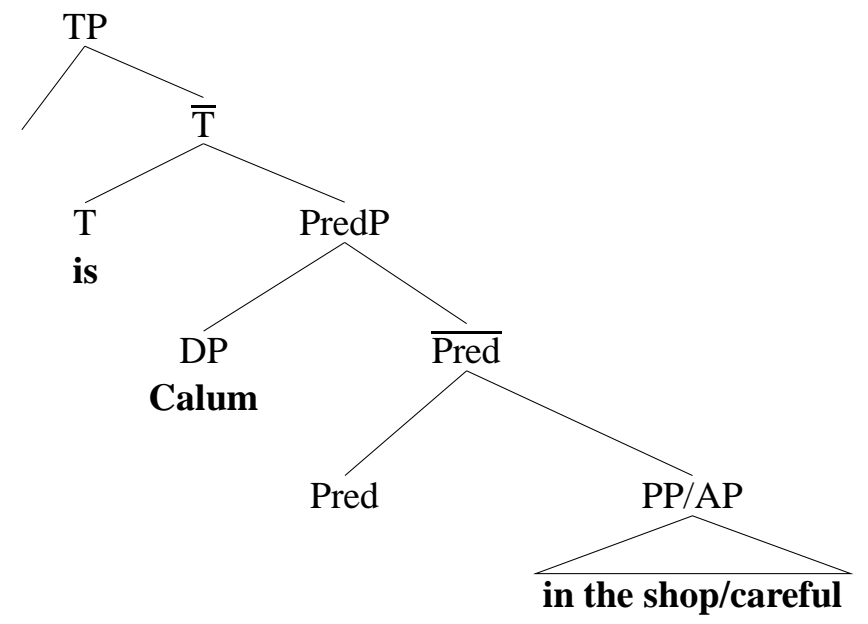

We adopt the same kind of analysis in the case of constructions where the little $\mathrm{v}$ head encodes some aspectual property, such as (8) above:

\footnotetext{
${ }^{2}$ The forms $b h a$ and tha are respectively suppletive past and present versions of the substantive auxiliary.
} 


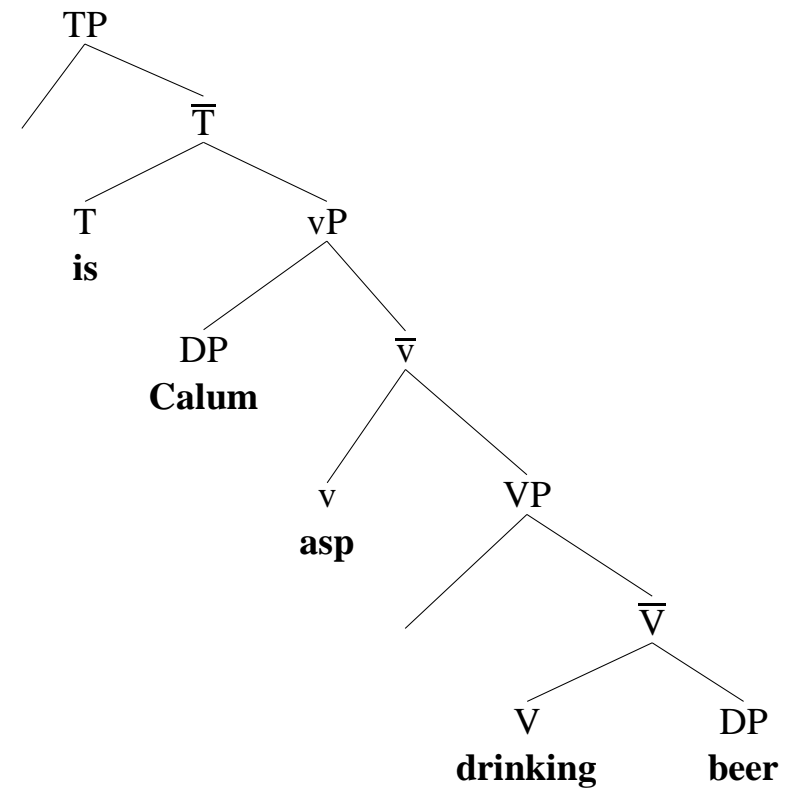

This approach predicts that the string Calum ag ò leann in (8) is a constituent independent of the appearance of the substantive auxiliary, a prediction which is backed up by the appearance of [Subj AspP/AP/PP] strings in small clause structures such as the tenseless absolutive construction in the following examples:

(13) Chunnaic mi Calum agus [e ag òl leann].

See-PAST I Calum and [ him prog drinking beer ]

'I saw Calum while he was drinking beer.'

(14) Chunnaic mi Calum agus [e air a mhisg].

See-PAST I Calum and [him on his drunkenness]

'I saw Calum while he was drunk.'

(15) Chunnaic mi Calum agus [e uamhasach toilichte].

See-PAST I Calum and [him terribly happy]

'I saw Calum while he was really happy.'

\subsection{Nominal predication and the Substantive Auxiliary}

We now turn to cases where the predicative core of the clause consists of two nominals. In such cases, a simple NP predicate is barred:

(16) *Tha Calum tidsear.

Be-PRES Calum teacher

'Calum is a teacher.'

(17) *Chunnaic mi Calum agus [e tidsear].

See-PAST I Calum and [him teacher]

'I saw Calum while he was a teacher.'

Similar facts are noted for Irish by Chung and McCloskey (1987). In place of a simple NP predication, we find a richer structure: 
(18) Tha Calum "na thidsear.

Be-PRES Calum in +3 sg teacher

'Calum is a teacher.'

(19) Chunnaic mi Calum agus [e 'na thidsear].

See-PAST I Calum and [him in-3MS teacher]

'I saw Calum while he was a teacher.'

The particle " $n a$ seen before the NP in these sentences consists, morphologically at least, of the preposition ann, "in," incorporating a possessive pronoun which agrees in $\phi$-feature specification with the subject, so as well as (18), we have (20):

(20) Tha mi 'nam thidsear.

Be-PRES I in +1 sg teacher

'I am a teacher.'

Why should there be this extra material? Under the system of assumptions we have built up so far, we might expect to be able to use the Pred head which cooccurred with APs, and PPs with NPs too, an expectation which is clearly not met.

We put this difference down to the different denotational properties of NPs as opposed to PPs, APs, and verbal constructions: NPs denote properties of individual entities, whereas APs, PPs and verbal constructions denote properties of individuals with respect to an eventuality. The idea that nominals lack an eventiality variable in their logical representation has been argued for by Higginbotham (1985) and Parsons (1990), among others. One way of expressing the distinction is to say that NP predicates are individual-level in this language, while APs etc. are stage-level. We follow Ramchand (1996) in taking the SAC in Scottish Gaelic to have an obligatorily stage-level type interpretation because the substantive auxiliary must bind an eventuality variable, and thus will reject the use of NP predicates as the complement of the null Pred head. Instead, the language employs an expletive prepositional head ann-'in' which by virtue of being a P possesses an eventuality variable, and also selects an NP complement. This PP projection is now possible as the complement of the null Pred head, which needs to bind an eventuality variable in its complement domain. In essence all that the overt prepositional head does is semantically convert the NP into a stage-level predicate with an appropriate variable position to bind (see Ramchand 1996 for details and evidence). ${ }^{3}$

The data we have presented so far does not constitute a challenge for the PredP approach to predication, and, in fact, provides some support for the existence of a separate predicative head. NP predication uses the same mechanisms as AP and PP predication, and in fact is unified with finite verbal structures at the right level of abstraction. All of these structures involve a predicative head which introduces an external argument and which enters into various feature-checking relationships with other heads and XPs in the structure.

However, it is worth noting at this point that, although NPs may be predicates within an SAC, DPs cannot be:

(21) *Tha Calum an tidsear.

Be-PRES Calum the teacher

'Calum is the teacher.'

This is equally true in other constructions which take a PredP, such as the absolutive construction we met earlier:

\footnotetext{
${ }^{3}$ Note here also that the aspectual heads found in Scottish Gaelic are also etymologically derived from a prepositional source, suggesting the naturalness of this kind of diachronic reanalysis of preposition to event structural functional head from a language internal point of view.
} 
(22) *Chunnaic mi Calum agus [e an tidsear].

See-PAST I Calum and [him the teacher]

'I saw Calum while he was the teacher.'

(23) *Bhuail mi Calum agus [e mo bhràthair].

Hit-PAST I Calum and [ him my brother]

'I hit Calum while/though he was my brother.'

(24) *Bhuail mi Calum agus e [an càraid as fheàrr agam].

Hit-PAST I Calum and him the friend best at-me

'I hit Calum while he was my best friend.'

Unlike in the case of NP predication, there is no way of "saving" this structure by using some extra morphological material, such as the ann particle we saw earlier:

(25) *Tha Calum anns an tidsear.

Be-PRES Calum in the teacher

'Calum is the teacher.'

Summarizing, then, whereas projections of lexical categories such as NP, PP, VP or AP may occur as the complement of Pred, DPs cannot. We return to a more formal discussion of this restriction in section 4.2.

\section{A Challenge: Inverted Copular Clauses (ICCs)}

In addition to the Substantive Auxiliary Constructions, Scottish Gaelic has another, more unusual, way of forming predicative structures. These constructions appear to involve the inversion of the predicate to a position in front of the subject, and we will therefore refer to them as Inverted Copular Constructions (ICCs). In Scottish Gaelic, inverted copular constructions are less productive than they were only a century ago, and, except for (an admittedly large number of) idiomatic locutions, they have an archaic flavour, or are high register.

\subsection{Copular Inversion structures}

Inverted copular constructions consist of the defective copula is/bu which is immediately followed by the predicate and then the subject. This verb has only these two forms, in contrast to the substantive auxiliary bith, which inflects for four tenses (present, past, conditional, future). The form is is used when the predication is present, while $b u$ marks past, future or conditional ${ }^{4}$ :

(26) Is mòr an duine sin.

Cop big that man

'That man is big.'

(27) Is le Calum an cù.

Cop-PRES with Calum the dog

'The dog belongs to Calum.'

\footnotetext{
${ }^{4}$ It may be that the functional head that appears within clauses of this type is not $\mathrm{T}$ at all, but a modal category signalling realis vs. irrealis features. We continue to assume the $\mathrm{T}$ functional projection here for concreteness, and because nothing crucial hinges on the particular properties of the functional head here.
} 
The copular verb here is phonologically weak and cliticises to the following predicate. There is evidence that the copula actually forms part of the onset of the syllable following it, suggesting it is incorporated into the following phonological word. This evidence is of two types: the is form of the copula is pronounced with a palatalised $s$ sound when a front vowel follows, a process which happens within but not between phonological words; if the copula is followed by an aspirated voiceless stop, this stop loses its aspiration, following a general restriction on aspirated stops in word initial $s$-clusters.

Example (26) shows an adjectival predicate, while (27) shows a PP predicate. There is no alternative order, with the subject preceding the predicate:

(28) *Is an duine sin mòr.

Cop that man big

'That man is big.'

(29) *Is an cù leamsa.

Cop-PRES the dog with+ me

'The dog belongs to me.'

As is shown by the translations, the predication in these examples is never tied to particular situations. The ICC always signifies that the predicate is conceived of as holding inherently of the subject, rather than accidentally. This contrast can be seen most clearly through examples like the following, where the use of the past copula is only felicitous if Calum is no longer alive. This is explained if the ICC, in contrast to the SAC, does not contain an eventuality variable. We return to the semantics of the ICC below.

(30) Is tidsear Calum.

Cop-PRES teacher Calum

'Calum is a teacher.'

(31) $\mathrm{Bu} \quad$ thidsear Calum.

Cop-PAST teacher Calum

'Calum was a teacher.'

Notice that NP predication follows the same pattern as AP and PP predication: the copular verb is followed immediately by the predicate, which in turn is followed by the subject.

A related restriction on the simple copular construction is that it does not tolerate bare existential subjects (32).

(32) *Is mòr duine.

Cop-PRES big a man

'A man is big.'

The lack of an existential reading is expected, given the individual-level nature of the predication. ${ }^{5} \mathrm{~A}$ detailed analysis of the interaction between generic and existential interpretations of nominals and the relation to the individual-level/stage-level distinction is beyond the scope of this paper (but see Ramchand 1996 for an analysis of the relevant constructions in Scottish Gaelic). We merely note the restriction here, and correlate it with the lack of eventuality variable in these constructions: we surmise that the default existential

\footnotetext{
${ }^{5}$ It is possible to have a generic reading of the bare nominal in this kind of sentence type. Ramchand (1996) shows that the bare nominal is not independently kind-referring (i.e. this is not a case of D-genericity in the sense of Krifka et al. (1995)) but that the generic reading arises from the binding of the individual variable provided by the nominal by a default Generic operator. Crucially, only this operator is available in ICCs, while default existential closure is only possible in SACs.
} 
closure found in stage-level propositions (Heim 1982, Diesing 1992) is responsible for the indefinite reading of common nouns in those constructions. This is absent in the inverted copular clause because of the lack of an eventuality variable.

The ICC might be thought to pose an immediate challenge for the PredP approach to predication, since the predicate appears on the 'wrong' side of the subject. There is a debate in the literature as to the exact analysis of these structures which we will only mention here (see Doherty (1996), Carnie (1995), Doherty (1997), Ramchand (1996), Cottell (1997) for fuller exposition, and see Rouveret (1996) for discussion of related questions in Welsh.) The two broad lines of attack can be characterised as follows: (i) these clauses are completely different in their structure from SACs and are built up from different syntactic atoms; (ii) ICCs are derived from SACs via inversion of the predicate phrase.

The empirical evidence which might allow us to choose between these two approaches is rather equivocal, and both approaches seem to be compatible with the data. In the interests of reducing predication to a single structural configuration, we will pursue the second strategy. We assume that the copula is a manifestation of the Pred head, and that it encodes the peculiar semantics of this construction (see below for our explicit proposal). The following shows the phrase structure we assume for sentence (33) below.

(33) Is leamsa an cù.

Cop-PRES with-me (emph) the dog

'The dog belongs to me.'

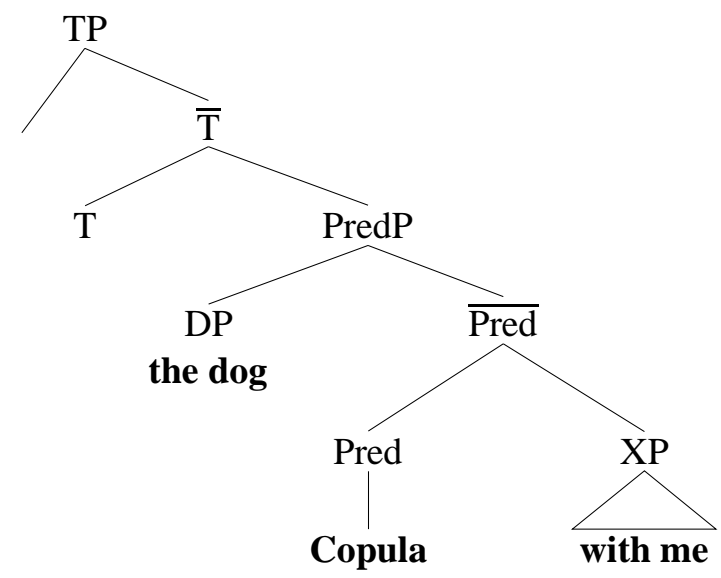

As before, we adopt the idea that $\mathrm{T}$ has the EPP property which must be satisfied by an element which the tense feature Agrees with. The extreme phonological weakness of the copula means that it cannot, on its own, satisfy the EPP property of T. This means head movement of the copula to adjoin to T does not take place. However, the $[u \mathrm{~T}]$ features of the copula are present on its projection, and so Pred $^{\prime}$ raises into the specifier of T. In essence the copula pied-pipes its complement to ensure that enough phonological material is carried along to satisfy the EPP requirement of T. ${ }^{6}$

\footnotetext{
${ }^{6}$ Note that within a Bare Phrase Structure type theory (Chomsky 1995a, Chomsky 1995b) Pred' is a syntactic object just like any other, and so may move and target a position where it can satisfy the EPP requirements of T. Unlike Carnie (1995), we do not assume that satisfaction of this requirement takes place adjoined to $\mathrm{T}^{0}$ but rather to $\mathrm{T}^{\prime}$.
} 


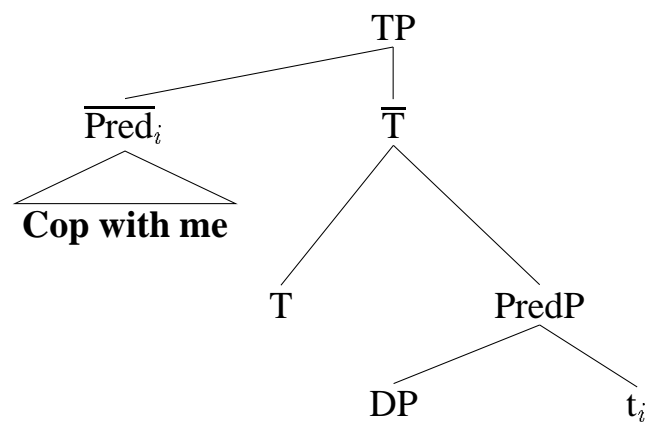

the dog

The ICC is reminiscent of a discussion in the literature about inverted copular structures in other languages. As mentioned in the introduction, Heggie (1988) and Moro (1997) argue that inversion of a predicate takes place in copular clauses in English examples like the following?:

(36) (a) Jenny is the teacher.

(b) The teacher is Jenny.

In both of these examples, these authors claim that the doctor is the predicate and has raised to its surface position, inverting over the subject.

However, although the ICC construction in Gaelic is reminiscent of these approaches, it cannot be reduced to them for a number of reasons. Firstly, whereas this kind of predicate fronting is restricted to definite DPs in English, as we have seen, it applies to all lexical categories except finite Vs in Gaelic. This gives the following minimal contrast, where an indefinite or bare NP cannot be fronted in English, but must be inverted in a Gaelic ICC:

$*(A)$ teacher is Jenny.

(38) Is tidsear Calum.

Cop-PRES teacher Calum

'Calum is a teacher.'

(39) *Is Calum tidsear.

Cop-PRES Calum teacher

'Calum is a teacher.'

Even more strikingly, the same generalisation that we saw with SACs also holds of ICCs: DPs are incompatible with the predicate position of an ICC.

(40) *Is an tidsear Calum.

Cop-PRES the teacher Calum

'Calum is the teacher.'

(41) *Is Calum an tidsear.

Cop-PRES Calum the teacher

'Calum is the teacher.'

\footnotetext{
${ }^{7}$ We discuss the case of English constructions in more detail in section 5
} 
Note that constructions with the defective copula in Pred accept NP as well as AP and PP as complements. This copula, unlike the substantive verb, does not require an eventiality variable to bind but rather predicates the property denoted by its complement directly of its subject. ${ }^{8}$ We assume that NPs denote simple atomic properties (see Chierchia (1984) and (4.1) for fuller discussion) and propose that the semantics of the defective copula is as follows:

$$
\llbracket \text { is } \rrbracket=\lambda \pi \lambda x[\operatorname{holds}(\pi, \mathrm{x})]
$$

Here, $\pi$ is the semantic type of simple properties. The copula's function is to state that the property denoted by its complement holds of its specifier. The lack of any variable signifying spatio-temporal location is what results in the distinction in interpretation between the defective copula and the substantive one. ${ }^{9}$

We noted earlier that these constructions were not fully productive in Scottish Gaelic, and this is also true in Irish for APs and PPs (Stenson 1981). We assume that this is because the defective copula in the colloquial language is now highly selective of the lexical items with which it can combine. However, the forms that do exist all conform systematically to the syntax and semantics we have outlined above, and our informants possess robust intuitions about them.

\subsection{A Further Challenge: Augmented Copular Constructions (ACCs)}

We have now seen the two major ways of constructing predicational structures in Scottish Gaelic: the SAC, where the predicate stays in situ unless it is a tensed verb, and the ICC where the movement of the copula pied-pipes the copula's complement, leading to an inverted structure. Both of these constructions can be profitably analysed as involving the PredP structure discussed in section (1), and neither is compatible with a DP predicate.

However, it is possible to join two DPs with the defective copula as long as an extra element appears. This extra element is morphologically a third masculine singular pronoun, and is traditionally termed the pronominal augment. We will therefore refer to these copular constructions as Augmented Copular Constructions (ACCs). In an ACC, the augment imediately follows the copula, which is then followed by the two DPs:

(43) 'S e Calum an tidsear

Cop 3sg Calum (DP1) the teacher (DP2)

'Calum is the teacher.'

Augmented copular constructions are not restricted to Scottish Gaelic and Irish. Pronominal elements appear in copular clauses in Hebrew (Doron 1988); Arabic (Eid 1983); Polish (Rothstein 1986); Zapotec (Lee 1999) and other languages. Our contention is that where such pronominals appear, they are the true predicates of the construction, which means that one of the DPs is interpreted via a link with this pronominal. We shall argue that this account both allows us to maintain a maximally simple relation between the syntax and semantics of predication, as well as explaining a range of empirical properties of these constructions.

\footnotetext{
${ }^{8}$ The intuitive difference between SACs and the ICCs shown in this section could be described in terms of the stage- vs. individual-level distinction of Kratzer (1995). However, we way we implement this does not involve a difference in lexical entries of predicates. Rather, we follow Ramchand (1996) in seeing the difference as a syntactic/semantic property of the construction: in the SAC the proposition involves the assertion of the existence of an event of a particular type; in ICCs, an atomic property is predicated directly of an individual.

${ }^{9}$ Note that this implies that APs and PPs also denote nominalised properties in these constructions. This seems to be the right result: ICCs are fully productive in Irish for NPs but restricted in a fairly idiosyncratic way for APs and PPs. Where APs are productive in this environment is in comparative forms, which have been independently argued to be nominalisations by Stenson (1977) and Adger (1999). See section (4.2) for further discussion.
} 
ACCs have been previously addressed in the literature on Irish copular constructions. Carnie (1997) argues that these constructions are true equatives, and that there is a null copula which takes two arguments and equates them (see also Zaring 1996). Under this view, the pronominal element is simply an agreement head (following proposals of Doron (1983) for Hebrew). Schematically, this analysis looks as follows:

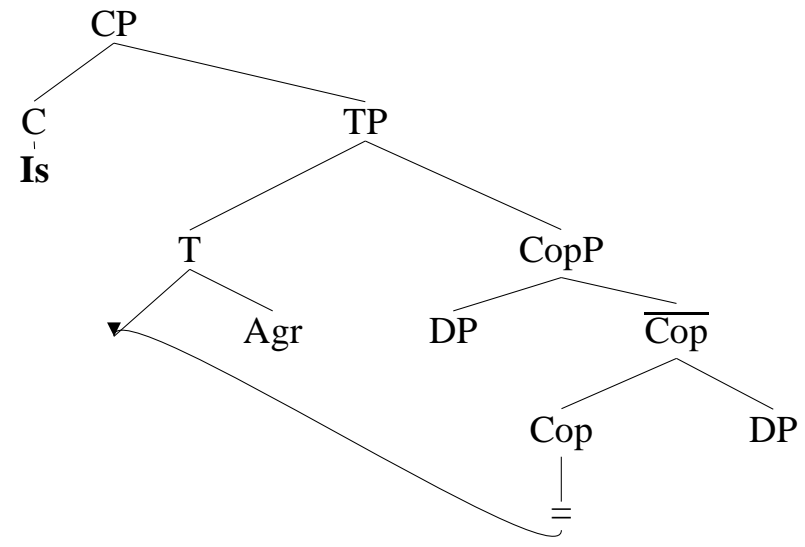

This proposal appears to receive support from considerations brought to bear by Heycock and Kroch (1999) who argue on the basis of sentences like (45), that true equatives really do exist:

(45) (a) Your attitude towards Jones is my attitude towards Davies.

(b) My attitude towards Davies is your attitude towards Jones.

In these examples it is difficult to treat one or the other of the two DPs as truly a predicate. Either one can be the syntactic subject with little apparent difference in interpretation. If such sentences exist in English, then one might be tempted to argue that this is what is going on in the Irish and Scottish Gaelic ACCs. However, there are a number of arguments against going down this path. Perhaps most strikingly, there is always an interpretive asymmetry between the two DPs in Scottish Gaelic (and also in Irish: see Stenson 1981). In (46), the only interpretation is that DP2, Hamlet is the name of a role. If we swap the two DPs around, it is impossible to interpret the sentence in the same way, even given world knowledge about actors and parts in plays:

(46) 'S e Sean Hamlet a-nochd

Cop he Sean Hamlet tonight

'Sean is (playing) Hamlet.'

(47) *'S e Hamlet Sean a-nochd

Cop he Hamlet Sean tonight

'Sean is (playing) Hamlet.'

We see here a contrast with what happens in other languages. Williams reports that the inverted sentences are fine in English (Williams 1983b), as does Pereltsvaig (2001) for Russian.

(48) Sean is Hamlet tonight.

(49) Hamlet is Sean tonight.

10

\footnotetext{
${ }^{10}$ We will give our account of the differences between English and Scottish Gaelic in section 5.3. In fact, we will argue that there are asymmetries in interpretation even in the English cases, which indicate syntactic and predicational asymmetries at work. But, regardless of the analysis given to the English cases, the point here is that it is impossible to avoid the conclusion that there is no identity predicate in the case of Scottish Gaelic.
} 
(50) Vysotskij byl Gamlet

Vysotsky-NOM was Hamlet-NOM

'Vysotsky is (playing) Hamlet.'

(51) Gamlet byl Vysotskij

Hamlet-NOM was Vysotsky-NOM

'Vysotsky is (playing) Hamlet.'

To further emphasise the point, an equality interpretation is simply not available in ACCs. This means that an example like (53) is not an appropriate translation of (52). The paraphrase in (54) must be used instead.

(52) Cicero is Tully.
(53) * 'S e Cicero Tully
Cop-PRES aug Cicero Tully
'Cicero is identical to Tully.'

(54) ' $\mathrm{S}$ e Cicero agus Tully an aon duine

Cop-PRES aug Cicero and Tully the same man.

'Cicero and Tully are the same person.'

Aside from the semantic asymmetry, there are a number of other difficulties with an equality predicate based approach to ACCs. Note that such an analysis makes these ACCs structurally identical to a true transitive verb construction, with the second DP in object position. Given this, one would expect that the first DP would behave just like the subject of a transitive verb, and the second just like an object. This expectation is not borne out in a number of ways.

Firstly, certain temporal and speaker-oriented adverbs are barred from appearing between the subject and object in a transitive sentence:

(55) * Chunnaic Mairi an uair sin Sean

See-PAST Mairi then Sean

'Mary saw Sean then.'

(56) * Chunnaic Mairi gu fortanach Sean

See-PAST Mairi fortunately Sean

'Mary fortunately saw Sean.'

However, these adverbs may appear between DP1 and DP2 in an ACC:

(57) 'B e Mairi an uair sin an tidsear

Cop-PAst Aug Mairi then the teacher

'Mairi was the teacher then.'

(58) 'S e Calum gu fortanach Hamlet a-nochd

Cop Aug Calum fortunately Hamlet tonight

'Calum is fortunately (playing) Hamlet tonight.'

Secondly, either the subject or object of a transitive verb may be questioned or relativised upon: 
(59) Cò $_{i}$ a chunnaic thu $t_{i}$ ?

Who saw you

'Who did you see?

(60) $\mathrm{Cò}_{i}$ a chunnaic $\mathrm{t}_{i}$ Calum?

Who saw Calum

'Who saw Calum?

However, speakers report that there are asymmetries in extraction from ACCs: DP1 is extractable, but DP2 is not: ${ }^{11}$

(61) Cò an tidsear/Hamlet?

Who the teacher/Hamlet

Answer: 's e Calum (an tidsear)/(Hamlet)

(62) ??Cò Calum?

who Calum

(seeking the answer: 'S e Calum an tidsear')

In addition, interpreting the augment as agreement raises problems of its own: in Scottish Gaelic, agreement is always in complementary distribution with overt DP arguments (see Hale and McCloskey 1984 for Irish and Adger 1996 for Gaelic); if the augment were an agreement marker, it would be the only agreement of its kind in the language.

The ACC then does look like a prima facie challenge for the strong claims made about the syntax and semantics of predicational structures in the introduction. It cannot be reduced to a transitive construction, and we have seen already that the Pred head in predicative constructions does not accept a DP complement.

We mention two further facts about ACCs that we believe any analysis of these structures should be able to account for. Firstly, no analysis assimilating ACCs to transitive clauses with agreement accounts for the generalisation that these structures have the property that the first DP after the augment is in presentational focus and receives the main sentence stress. An extremely natural way of answering a wh-question like (61) above is by using the appropriate ACC, with the new information occurring immediately after the augment. It is impossible to answer this question with the DPs the other way around:

(63) Cò an tidsear?

Who the teacher?

Answer: 's e Calum an tidsear.

Answer: * 's e an tidsear Calum.

The focus properties of the ACC are especially striking considering that, in all other cases, nuclear stress always falls on the rightmost stressable element of the final phrase in the clause, unless some dislocation operation has taken place:

(64) Chunnaic Màiri SEAN

See-PAST Mairi Sean

'Mary saw Sean.'

\footnotetext{
${ }^{11}$ Stenson (1981) reports that such asymmetries are also marked in Irish, although she does not give the same judgement as we report here. All that we wish to emphasis is that there is a contrast between the behaviour of the ACC and that of simple transitive clauses. The marked nature of these constructions appears to be dependent on their informational status, which, in section (4.4) we tie down to their syntax.
} 
The second fact about ACCs is that they involve the same morphological material as ICCs. An analysis which treats the ACC as involving an equality predicate misses this generalisation.

In the next section, we will argue that, despite appearances, we do not need to allow a different structure for the kind of predication that involves two DPs. We will analyse ACCs as a subtype of ICCs, involving the copula. We will argue that the augment is the predicate in these constructions, and that it inverts with the subject in the same way that other predicates in copular clauses do. The difference between ACCs and ICCs is not really the augment, it is rather the presence of an extra DP which is semantically linked to the augment, in much the same way as DPs are linked to argumental pronouns in pronominal argument languages (see Jelinek 1984).

\section{Analysis of ACCs}

At this stage, it is clear that definite DPs give rise to serious deviations from the normal predicational structures found in this language. We will argue that the special status of these DPs derives from their semantics, and moreover that the semantics of nominal projections is correlated with their syntactic status within an articulated DP projection (Zamparelli 2000, Longobardi 1994). Firstly, we lay out our assumptions concerning the number and type of projections found within the DP, assumptions based on Zamparelli (2000). Then, we analyse the different types of nominal projection found in Scottish Gaelic and demonstrate the way in which pronouns, proper names, and common nouns pattern together to the exclusion of definite DPs. We use these results together with the semantics of the copula given in section (3.1) to motivate the existence of pronominal predicates in copular constructions. Finally, we show how the analysis of ACCs as involving a pronominal predicate related to a right-adjoined nominal phrase accounts for all the syntactic, semantic and discourse related properties of the construction and allows us to maintain the idea that there is only one underlying predicational structure in the language.

\subsection{The Semantics of DPs}

We follow Zamparelli (2000) in decomposing the DP into different layers of functional projection. Zamparelli argues on the basis of a wide range of data from English and Italian, that (i) three distinct semantic types can be distinguished within nominal projections, and (ii) these semantic types correlate with distributional and morphological facts to motivate a straightforward one-to-one mapping between syntactic projection and the semantics. These levels of projection and their semantic correspondences are shown below in (65).

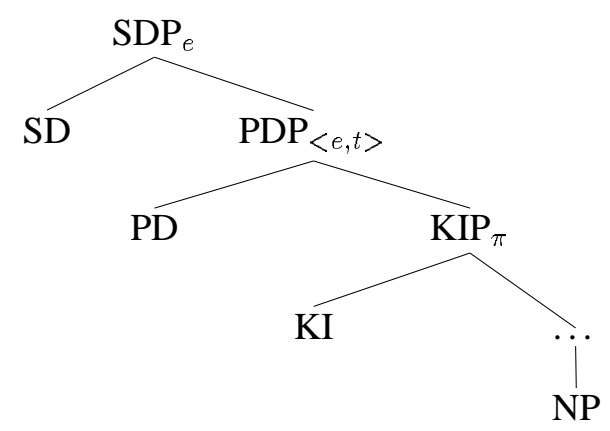

According to Zamparelli, the only truly referential part of the nominal projection is the element heading the Strong Determiner Phrase (SDP) position. At this level the DP is of semantic type e. 12 The PD projection is the site of numerals and of certain types of adjectives, it is a Predicative Determiner Phrase of

\footnotetext{
${ }^{12}$ Zamparelli assumes, in addition, that all quantified phrases raise at LF, leaving behind a variable of type e. We will not be concerned with quantified NPs in this paper.
} 
type $\langle\mathrm{e}, \mathrm{t}\rangle$. The KIP, the Kind Determiner Phrase, is the phrase which denotes an atomic property, or a kind (related to the nominalised properties of Chierchia (1984)). We have already appealed to such a semantic type in our discussion of the semantics of the defective copula. There, we proposed that the defective copula is/bu takes an atomic property of type $\pi$ as its argument and predicates this property of its subject.

Thus, Zamparelli argues for the following correspondences between projections in nominal phrases and their syntactic/semantic distribution:

- SDPs are referential, and only they can appear in argument positions 'The dog is barking.'

- PDPs are predicative and can appear in certain contexts which host, for example, APs 'Fido is a dog.'

- KIPs represent pure properties, and can appear, for example, as the complement of the 'kind of' construction in English.

'This is a friendly kind of $\mathbf{d o g}$.'

We adopt this basic proposal, that there are layers of projection within the nominal phrase, and that these layers correspond to distinct semantic types in a one-to-one fashion. This proposal clearly fits in well with the general perspective on the syntax semantics interface that we adopt. We will show that, for Scottish Gaelic, at least two of these levels can be independently motivated: the referential SDP level, and the property-denoting or KIP level. ${ }^{13}$

The semantics associated with SDP and PDP are familiar enough. We assume a semantics for the head KI of KIP which results in KIP denoting an atomic property:

(66) $\llbracket \mathrm{KI} \rrbracket=\lambda \mathrm{x}[\iota \pi$ : where $\pi$ is the relevant distinguishing property associated with $\mathrm{x}]$

Take a case where the head of KIP combines with the lexical root $d o g$. Once the KIP layer has been projected, we have the following semantics:

(67) $\llbracket \mathrm{KIP} \rrbracket=[\iota \pi$ : where $\pi$ is the relevant distinguishing property associated with $\mathrm{dog}]$

Other approaches are compatible with what we will say below, as long as the KIP denotes some kind of an atomic type associated with spatio-temporarily undifferentiated properties (see Carlson 1977, Chierchia 1984 for different approaches).

Within Zamparelli's system, there are a number of different ways in which the referential level of projection (the SDP) can be instantiated in natural languages. Firstly, languages may come equipped with lexical determiners that are of category SD. It can also be argued that some pronouns, e.g. clitic pronouns in Italian, are base generated in SD (see Cardinaletti 1993 for a proposal along these lines). Secondly, some Ns can bear a feature which allows them to raise from the lowest position to fill the SD slot of the extended projection. This is plausibly the case with proper names and some pronouns (cf. Longobardi 1994). A third possibility is the insertion of an expletive determiner in the SD position, if one exists in the lexical inventory

\footnotetext{
${ }^{13}$ We will not make use of Zamparelli's PDP projection in what follows. In our analysis, nominal phrases have only two distinct semantic types: property-denoting or individual denoting. The PDP layer, if it exists in Scottish Gaelic, appears to be syntactically and semantically inactive and we have been unable to identify any empirical effects. However, the analysis we will develop is, with minimal elaboration, broadly compatible with the existence of such a projection. If it truly turns out to be the case that PDP is always inactive in Scottish Gaelic, then this raises interesting questions about the limits of syntactic and semantic variation language allows. In our system, the projection that is interpreted as being of type $<\mathrm{e}, \mathrm{t}>$ is PredP, and it can select for any projection which is property denoting, regardless of its syntactic category.
} 
of the language. ${ }^{14}$ In the case of common nouns, a null expletive head can be generated to create SDPs when found in argument position. In general within this framework, null expletive SD heads need to be bound by anaphoric reference or default existential closure to be semantically well-formed (see Zamparelli 2000:sec 4.4).

Within this overall framework, we will argue that Scottish Gaelic nominals come in two flavours: SDP and KIP. Crucially, we will show that pronominal elements may be bare KIPs in positions where they are not arguments. This will open up the way to an analysis of ACCs.

\subsection{Nominal Projections in Scottish Gaelic}

In comparing Scottish Gaelic nominal phrases with their English counterparts, the most obvious difference is that Scottish Gaelic possesses an overt definite determiner (see (68)), but no indefinite one (69).

(68) an tidsear - the teacher

(69) tidsear - a teacher

The form in (68) is obligatorily definite, and as we have seen, may never appear as the complement of Pred in a small clause selected in SACs by the substantive auxiliary bith (70) (unlike nominal phrases headed by 'the in English), or as the complement of the copular Pred head is in ICCs (71).

(70) *Tha Calum an tidsear.

Be-PRES Calum the teacher

(71) * Is an tidsear Calum.

Cop-PRES the tidsear Calum

From this evidence, we infer that Scottish Gaelic definite determiners are base generated in SD, and that DPs headed by such determiners are obligatorily SDP and can only appear in non-predicative positions. In particular, they can never denote properties and therefore never appear as the complement to Pred.

On the other hand, a bare determinerless nominal can have the meaning of either a nonspecific indefinite (72), or a specific indefinite (73):

(72) Tha mi a'lorg tidsear.

Be-PRES I seeking a teacher

'I am looking for a teacher.'

(73) Bha tidsear ann an seo a-raoir.

Be-PAST a teacher in here last night

'There was a teacher in here last night.'

This indicates that determinerless nouns in Scottish Gaelic can also project to full SDPs and appear in argument position. In general then, nominals may project the SDP layer in argument positions. Nominals with overt determiners are obligatorily SD by virtue of the category of the determiner, while bare nominals project to SD by virtue of the fact they are in argument positions.

\footnotetext{
${ }^{14}$ Zamparelli argues that some dialects of Italian possess such null expletive determiners for proper names, as opposed to others which raise proper names to SD.
} 
We implement this observation by adopting Zamparelli's idea that certain DPs may contain expletive determiners in SD. Bare NPs in argument position contain an SD layer with an expletive determiner. The projection of SD in argument positions can be forced by assuming that SD is the locus of Case features in the language. Since DPs in argument positions require Case, they have to project to SD. Recall that the ability of the bare noun to get an existential interpretation (whether specific or not) is dependent on the existence of an eventuality variable in the representation. The binding of the individual variable introduced by the null expletive SD head in these cases is achieved via default existential closure triggered by the existence of an eventuality variable. Recall also that in individual-level constructions (specifically, the ICC), bare nouns are impossible as existential subjects of predication, due to the lack of an appropriate binder that semantically identifies the variable supplied by the SD head.

In addition to its use as an argument, the bare noun can also appear as the predicate in the SAC (74) and in these circumstances the particle ann inflected with $\phi$-features appears. We showed in section (2.2) that whereas adjectives and prepositions could provide an event variable for the null Pred head to bind, an expletive prepositional head is required with nominals, since nominals lack an eventuality variable of their own. This expletive prepositional head appears as $n a$ in (74).

(74) Tha Calum 'na thidsear.

Be-PRES Calum in+agr teacher

'Calum is a teacher.'

We assume, then, that bare nouns are KIPs where the function of the KI head is to turn the lexical concept expressed by the root into a property, in the way discussed in (4.1). In (74) Pred combines with a bare KIP and adds an eventuality variable into the representation. Note that the complement of Pred is not a Case position, and so no expletive SD is generated.

Bare KIPs may also appear as the complement of the defective copular Pred head in the ICC (75), where they are again Caseless. We argued in section (3.1) that the Pred head in an ICC does not contain an event variable but rather predicates the atomic property directly of its subject, leading to an interpretation analogous to the individual level predication of Kratzer (1995):

(75) Is tidsear Calum.

Cop-PRES teacher Calum

'Calum is a teacher (by vocation).'

We will assume that APs and PPs also combine with the KI head in ICC constructions, and that this combination is lexically restricted, accounting for the differential productivity of these categories. The KI head nominalises the eventuality-bearing predicate expressed by the AP or PP. As mentioned in section (3.1) there is independent evidence for the idea that APs and PPs are nominalised in ICCs.

In summary, then, nominal projections in Scottish Gaelic are either SDPs, in which case they are may appear in argumental positions, or they are KIPs, in which case they occur as the complement of some Pred head.

The next main categories of nominal we need to examine are proper names and pronouns. Once again there is cross-linguistic variation in how these elements are syntactically represented. There are at least three ways in which pronouns and/or proper names can give rise to SDPs in Zamparelli's sense: (i) they could be base generated in SD (as in the case of Romance clitic pronouns); (ii) they could possess a null expletive determiner (as in some varieties of Italian) or (iii) they could raise from the base position to the SD functional head. If (i) were the case, we would expect pronouns and proper names to pattern with DPs headed by overt determiners in Scottish Gaelic in not appearing as the complement of a Pred head. However, if either (ii) or (iii) is the case in Scottish Gaelic, then we would expect that they would pattern with bare nouns in allowing the less articulated property-denoting projection, side by side with the full referential 
projection of SDP. SDP would be obligatorily projected in positions where the pronouns check Case, while KIP projections would be licensed elsewhere.

We show that the evidence is that pronouns and proper names do not pattern with the full determiner nominals of the type shown in (68). In what follows, we will concentrate on the analysis of pronouns, since they will be crucial to our analysis of the augment in ACCs, but we will also make passing reference to the facts concerning proper names as well.

\subsection{Pronominal Predicates}

There is interesting evidence that pronouns in Scottish Gaelic are not generated directly in SD. This evidence comes from a peculiar agreement marking on prepositions (see Adger 2000 for fuller discussion of the contexts for prepositional inflection).

Consider the following paradigm. In Scottish Gaelic, prepositions change form depending on whether the DP following them contains an overt determiner. Thus, in (76) we see a preposition $r i$, 'with' in its plain form; while (77) shows what we will call its D-agreeing form ris when it occurs with a determiner headed nominal.

(76) ri tidsear

with-INDEF. tidsear

'with a teacher'

(77) ris an tidsear

with-DEF. the teacher

'with the teacher'

(78) ris na tidsearan

with-DEF. the-PL teachers

'with the teachers'

(79) $*$ ri $\quad$ an tidsear

with-DEF. the teacher

'with the teacher'

The same agreement appears on prepositions with the determiner gach, 'each/every':

(80) ris gach tidsear

with-DEF. the teacher

'with each teacher'

(81) *ri gach tidsear

with-DEF. the teacher

'with the teacher'

D-agreement does not occur with bare nouns (76), or with nouns which have adjectival quantifiers or numerals:

(82) ri/*ris mòran tidsearan

with-DEF. many teachers

'with many teachers' 
(83) ri/*ris trì tidsearan

with-DEF. three teachers

'with three teachers'

We will not develop an analysis of this construction here (see Adger (2000)), but will simply appeal to the generalisation that D-agreement appears on the preposition when there is an overt element in SD. Under the analysis developed in section (4.2), bare NPs contain a null expletive determiner in SD, and so do not trigger D-agreement.

With pronouns, the parallel cannot be made in its most straightforward form, since pronominal objects of prepositions in PPs always appear as pro with agreement appearing on the preposition (84).

(84) rium

with-1 SG 'pro'

'with me'

(85) rithe

with-3FSG 'pro'

'with her'

The presence of $\phi$-features on the preposition means that it is impossible to determine whether the following pro is triggering D-agreement. However, there is another context where D-agreement shows up, and where the nominal is not the actual complement of the preposition. The contexts in question concern sentences which contain what looks like the equivalent of exceptionally case marked subjects. Consider (86) below, where the preposition ri selects a whole clausal complement, and appears in its ris form with the determiner-headed nominal in subject position of the non-finite clause. See Adger (2000) for motivation for this structure:

(86) Dh'fheuch mi ris [an leabhar a leughadh].

try-PAST I with-DEF [the book to read]

'I tried to read the book.'

Crucially, when the subject of the nonfinite clause is a bare nominal, the preposition $r i$ reverts to its bare form (87).

(87) Dh'fheuch mi ri [leabhar a leughadh].

try-PAST I with-INDEF. [book to read]

'I tried to read a book.'

The interesting case for us is what happens when the subject of the nonfinite clause is a pronoun: it turns out that the preposition retains its bare form (88). ${ }^{15}$

(88) Dh'fheuch mi ri [esan a bhualadh].

try-PAST I with-INDEF. [he-EMPH to hit]

'I tried to hit HIM.'

All of these nominals are SDPs since they appear in argument positions. However, since pronouns in Scottish Gaelic do not trigger a change in prepositional form, they are not base generated in SD nor do they obligatorily raise there, unlike clitic pronouns in Romance. This eliminates options (i) and (iii), set

\footnotetext{
${ }^{15}$ We use the emphatic form of the pronoun here, because the non-emphatic pronoun is obligatorily realised as pro in this position.
} 
out at the end of section (4.2) and suggests an analysis where pronouns occurring in argument positions are SDPs by virtue of a null expletive determiner. ${ }^{16}$ This predicts that in contexts where Case is not checked, it should be possible to find pronouns in KIP, with a property denotation. The relevant context is of course the complement position of Pred. This prediction is confirmed: pronouns are well-formed in the complement position of the copular Pred head, as the examples in (89) and (90) attest. ${ }^{17}$

(89) Is mise Catriona.

Cop-PRES me Catriona

'I am Catriona.'

(90) Is iadsan na h-oileanaich.

Cop-PRES they the students

'They are the students.'

On the other hand, pronouns cannot appear as the complement of the null Pred head found in bith clauses, as we saw in section (2.2). We repeat the example here:

\section{(91) *Tha Calum mise. \\ Be-PRES Calum mise \\ '??Calum is me.'}

However, this is straightforwardly accounted by the fact that pronouns are implausible stage-level predicates; interpretations constructed by combining a pronoun with an eventuality variable are pragmatically ill-formed. Interestingly, it is marginally possible to force proper names to appear in an SAC in special contexts, where a spatio-temporally bound interpretation is forced, such as the following:

(92) Tha e na Einstein an diugh.

Cop-PRES he in-his Einsten today

'He's being an Einstein today.'

This contrasts sharply with the ungrammatical cases with SDPs we saw in (2.2), where it is not even clear to native speakers how to do the appropriate morphology.

To summarise, the morphology and distribution of pronouns in this language is consistent with them allowing both KIP and SDP syntax, showing that they are not generated in SD. Assuming that pronominals are really functional categories, it follows that they are simply KIs in Scottish Gaelic. The particular interpretation we associated with KIPs in section (4.1) can be straightforwardly carried over to pronouns, with the caveat that there is no root category for the KIP to attach to. We suggest the following interpretation for pronouns:

(93) $\llbracket$ KIP $\rrbracket=[\iota \pi$ : where $\pi$ is the relevant distinguishing property associated with some contextually given individual $\mathrm{x}$ ]

where the interpretation of $\mathrm{x}$ is filled in by the context, and constrained by the grammatical features of the pronoun. Given the interpretation of the defective copula that we motivated in section (3.1), an example like (90) has a paraphrase like that in (94):

\footnotetext{
${ }^{16}$ The data from proper names is exactly the same as for pronouns here: no D-agreement is triggered either in the simple PP cases or in the nonfinite clause cases.

${ }^{17}$ Proper names, on the other hand are never good in this position in SGaelic. This is not surprising, given the highly restricted set of lexical items that can be selected by the copula in the modern language.
} 
(94) 'The relevant distinguishing property associated with a plurality of some contextually given individuals' holds of 'the students'

In this particular case, the relevant distinguishing property might be identified via deixis, or anaphora, depending on the context of the utterance.

In the next section, we exploit this set of ideas about simple copular clauses to provide a natural (but to our knowledge novel) analysis of the Augmented Copular Construction.

\subsection{The Syntax and Semantics of ACCs}

Recall the analysis we developed for ICCs in section (3.1). The idea was that the defective copula headed PredP, and combined with a property denoting element. We gave the following rough semantics to the copula:

(95) $\llbracket$ is $\rrbracket=\lambda \pi \lambda x[\operatorname{holds}(\pi, \mathrm{x})]$

In order to satisfy the EPP property of T, the copula raises and pied-pipes its complement, ending up in the specifier of TP. This means that an example like (96) has a structure like that in (97):

(96) Is tidsear Calum

Cop-PRES teacher Calum

'Calum is a teacher (by nature or vocation).'

(97)

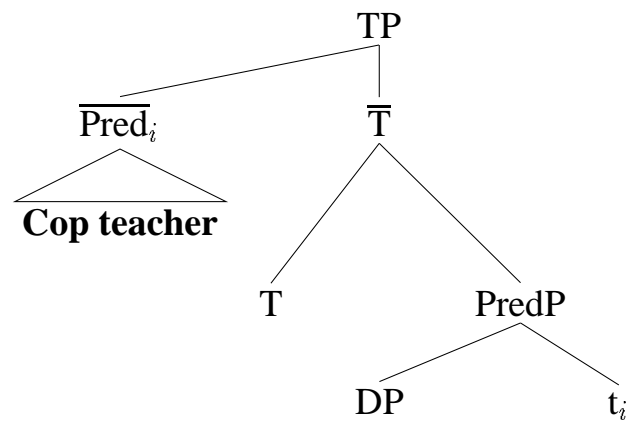

Calum

The bare nominal here is a KIP, is the complement of the copula, and raises with it to the specifier of TP.

Now recall that we have shown that pronouns may be KIPs with a KIP interpretation. Our expectation is that pronominals may also occur as complements to the defective copula, and we saw cases of this in section (4.3). If we take an unmarked, third person masculine pronoun, we predict the following well-formed structure:

(98)

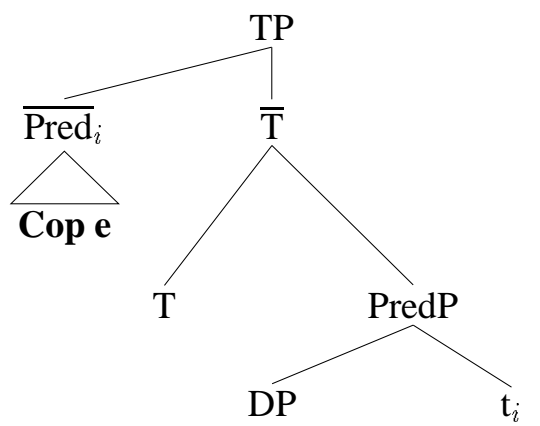

Calum 
This derivation, under the assumptions we have defended so far, predicts the well-formedness of (99), with the interpretation in (100):

(99) 'S e Calum.

Cop-PRES Aug Calum

'It's Calum.'

(100) 'The relevant distinguishing property associated with some contextually given individual' holds of 'Calum'.

In fact such sentences are perfectly well formed, and are used as answers to wh-questions, or as exclamations to introduce someone after some event has taken place (such as someone knocking at the door). Clearly the interpretation given in (99) is exactly correct for these situations. In wh-questions, the relevant distinguishing property is that given by the stated content of the question, while in the exclamation case it is supplied directly by the context.

This particular result immediately offers us a way of understanding ACCs: the augment is no more than a pronominal generated in the complement of Pred, with exactly the interpretation of a KIP pronoun. The DP which appears immediately after the augment is simply the subject of the construction, while the second DP is right adjoined. The right adjoined DP's function is to explicitly identify the 'contextually given individual' in the semantics of the pronominal augment with overt linguistic material.

The way that this identification takes place is via a purely semantic operation, akin to cross-sentential anaphora, or apposition. The adjoined SDP fills in information within the semantic representation of the pronoun without reference to any syntactic agreement or coindexing information, in much the same way as certain appositional phrases can. See (101) in Spanish (and its English translation) for a situation where the subject pronoun and the coreferential left-adjoined phrase are mismatched in number and person features.

(101) Las mujeres somos contentas.

The women 'pro'-1 PL/F be-1 PL happy

'We, the women are happy.'

The operation of referential identification of the augment with the right-adjoined DP is a case where the semantic mechnisms and the syntactic specification is decoupled. Although the mapping between the syntax and the semantics is tightly constrained, there are purely autonomous semantic operations which establish this kind of effect.

Take an example like (102):

(102) 'S e Calum Hamlet.

Cop he Calum Hamlet

'Calum is Hamlet.'

The interpretation predicted is given in (103):

(103) 'The relevant distinguishing property associated with some contextually given individual' holds of 'Calum'.

Where: The contextually given individual is referentially identified with 'Hamlet'.

Clearly this interpretation, in conjunction with world knowledge about what names are parts in plays, gives the right meaning for the example. If the two DPs are swapped around, the sentence is perfectly grammatical, but clashes with our word knowledge, and appropriate contextualisation renders it perfectly 
acceptable (if, for example, Calum is a part in a play and Hamlet is an actor). In general, the meaning of the second DP forms part of a property description, which accounts for the role interpretation.

This approach also correctly explains the fact that ACCs can never have the meaning of pure identity statements, and require the paraphrase discussed in section (3.2). There is no identity statement in the semantic representation which is built up on the basis of the syntactic atoms and they way they have been combined. Instead, there is always a predicational asymmetry stemming from the fact that an ICC ascribes a property to an individual.

In addition to correctly predicting the interpretational asymmetries observed in ACCs, the idea that the second DP is adjoined rather than being a true argument explains the fact that adverbs may occur between the two DPs of an ACC, in contrast to the impossibility of adverbs between the subject and object of a transitive sentence. We repeat the relevant data here:

(104) * Chunnaic Mairi an uair sin Sean.

See-PAST Mairu then Sean

'Mary saw Sean then.'

(105) 'B e Mairi an uair sin an tidsear.

Cop-PAst Aug Mairi then the teacher

'Mairi was the teacher then.'

The adjoined nature of this second DP also explains why it does not take the primary sentence stress, in apparent violation of normal clausal stress patterns in the language. The semantic function of the DP is to provide information usually given by the context, since this is the interpretation of the augment. As such, this DP signifies backgrounded information, and is destressed. The same fact accounts, of course, for the focus properties of this construction. Since there are essentially only two major constituents in the proposition, and one is destressed, the other is obligatorily in focus. It is this that also accounts for the strict constraints on the two DPs in an ACC which answers a wh-question:

(106) Cò an tidsear?

Who the teacher?

Answer: 's e Calum an tidsear.

Answer: * 's e an tidsear Calum.

Since the DP immediately after the augment (the subject) is in focus, only it can felicitously serve as the element that introduces the new information required by the fact that the utterance is being used to answer a wh-question.

The analysis we present here also explains why only a definite DP can appear in the second position in an ACC:

(107) 'S e Daibhidh *tinn/*tidsear/an tidsear.

Cop-PRES aug David sick/teacher/the teacher

'Its David who is *sick/*a teacher/the teacher.'

(108) 'The relevant distinguishing property associated with some contextually given individual' holds of 'David'.

Where: The contextually given individual is referentially identified with 'the teacher'.

Since the function of the pronominal predicate is to provide a property containing reference to an individual which needs to be contextually specified, the role of the right-adjoined element is to identify that individual. Thus, the right adjoined element must be an SDP. Recall that bare NPs are KIPs and only project 
to SDP when they are arguments (a fact which is perhaps related to Case). This means that an SD determiner must be present in the adjoined DP, or else the adjoined DP would not be referential, and would not be able to identify the relevant individual.

Finally, the restrictions on the subject of an ACC also follow directly on our account. The defective copula states that a property holds of some individual, as an inherent fact. Thus, the subject of such a clause must be individual denoting. We saw that in the simple ICC construction, the subject position had to be a name or a determiner-containing definite because of the restriction of bare NPs to eventive predication. That restriction carries over straightforwardly to the first Nominal of the ACC, since under our analysis this position is identical to the Subject position of a simple ICC.

The approach we have developed here is remarkably successful in explaining a range of semantic and syntactic facts about the ACC which appear, at first, to be seemingly unrelated. Furthermore, it does so on the basis of plausible and independently motivated syntactic and semantic specifications for the constituent parts of the ACC, so that the apparently peculiar properties of the ACC are all reduced to well-motivated properties of other constructions. Perhaps most importantly, the ACC no longer constitutes a challenge, in this language at least, to the idea that predication is always constituted via the same basic syntactic structure.

\section{Linguistic Variation in Copular Constructions}

The hypothesis we have been exploring here is that apparently different types of predicational structure all reduce to one underlying case. In Scottish Gaelic, the differences arise because of the particular semantic specification of the predicational head (whether it is eventive or not) and its syntactic and phonological properties (how and where it satisfies EPP). This particular language has no identity predicate and obligatory projection of SDP. The use of a pronominal predicate to link two DPs is one of the strategies that can be followed. In this section we explore how this strategy might be adopted in slightly different guises by a range of other languages.

\subsection{Polish}

Polish marks the distinction between temporary/accidental properties and inherent properties not with different copulas, but rather via case marking. A predicate NP or AP which is eventive is marked with instrumental case (109), while an individual-level predicate is marked with nominative (110):

(109) Ewa jest studentką.

Eva be-PRES student-INSTR.

'Eva is a student.'

(110) Ewa jest studentka

Eva be-PRES student-NOM

'Eva is a student.'

Rothstein (1986) describes the difference between the two examples above in the following way: the instrumental version is the neutral unmarked version of the sentence; while the nominative one is more affective and indicates a closer psychological identification of the subject with being a student. Here, we assume that the verb być-'be' in Polish is simply a tense carrying functional head. Under the system we have developed here, two different predicational heads are implicated in this distinction. The eventive head checks instrumental case of its complement, while the non-eventive head (corresponding to the defective copula in Scottish Gaelic) checks nominative. Interestingly, like the Scottish Gaelic ICCs, the structures shown in (110) are reported to be more restricted than the ones of type (109), although, again like Scottish Gaelic they are commonly used for simple statements of identity such as 'I am Janek' (111). 
(111) Janek jestem.

Janek-NOM be-PRES1SG

'I'm Janek.'

When two definite DPs are to be identified, neither of these structures is possible. Instead, Polish requires the use of a pronominal demonstrative element to link the two SDPs, as in (112), but allows być-'be' plus the instrumental case when the ascription is predicative (113).

(112) Ta pani to premier Anglii.

This woman DEM-3SM premier-NOM England-GEN

'This woman is the premier of England.'

(113) Ta pani jest premierem Anglii.

This woman be[PRES, 3SM] premier-NOM England-GEN

'This woman is a premier of England.'

Under the analysis proposed in this paper, the use of a pronoun in precisely these identificational contexts is not accidental, but derives from the strategy of using pronominals to construct predicational structures, while allowing them to be referentially identified with the predicationally inert SDPs in the language.

\subsection{Modern Hebrew}

Another well known case of a language in which pronouns are implicated in the construction of identity statements is Hebrew. Once again, we suggest that the existence of the pronoun is not accidental but derives from a strategy similar to the one we have already seen for Scottish Gaelic.

To summarise briefly, nominal sentences in the present tense contain a third person pronoun as shown in (114) below.

(114) dani hu more.

Danny pron-3MSG teacher

'Danny is a teacher.'

Doron (1983) argues that the pronoun is not a tensed verb, but is simply the realisation of agreement features and is located in Infl. In Hebrew, the pronoun is optional in many situations, but there are contexts in which the deletion of the pronoun is not possible. Many researchers (Doron 1983, Rapoport 1987, Rothstein 1995) have argued that the descriptive generalisation is that the pronoun is obligatory in identity predications such (115), but optional in predicatives such as (116). ${ }^{18}$

(115) ha-horim Seli *(hem) shira ve-yosi kats

the parents mine pron-3MPL Shira and Yosi Kats

'My parents are Shira and Yosi Kats.'

(116) Bill Clinton xaxam /ba-xeder Seli /more le-'anglit

Bill Clinton wise /in the-room mine /teacher to-English

'Bill Clinton is wise/in my room/an English teacher.'

However, Greenberg (1997), Greenberg (1998) points out that this descriptive generalisation is not quite right. There are other contexts in which the pronoun is obligatory where there is no statement of identity being made. Consider the contrast between (117) where the pronoun is obligatory and (118), where it is not.

\footnotetext{
${ }^{18}$ The data here is taken from Greenberg 1997.
} 
(117) zmaxim *(hem) yerukim

plants pron-3MPL green

'Plants are green.'

(118) ha-zmaxim ha-ele (hem) yerukim

the plants these pron-3MPL green

'These plants are green.'

Greenberg claims that the crucial generalisation is that of genericity, with the pronoun being the "overt syntactic marker of genericity" in this language.

There are problems with both sorts of descriptive claim here. On the one hand, the proposals of Doron (1983), Rapoport (1987) and Rothstein (1995) cannot account for why the pronoun is obligatory in these generic contexts, while it is mysterious under the system developed by Greenberg (1998), why the pronoun should be obligatory in non-generic identity contexts.

The analysis we have proposed in this paper has the virtue being able to unify the two contexts straightforwardly. First of all, notice that in Scottish Gaelic, both identity statements and attributions of a permanent property to an individual are constructed using the defective copula, is, not the substantive auxiliary. They form a natural class because they both involve property predication over an individual as opposed to involving an eventuality variable.

The difference between the identity statements (ACCs) and the simple property predications (ICCs) is that the former involves the postulation of a pronominal predicate to mediate the relation between the two SDPs while the latter does not. This is because of the strict syntactic and semantic requirements of Pred. In accounting for the Hebrew data, we need only assume that grammaticalisation has led to reanalysis of this pronominal predicate, and that the pronoun $h u$ (in its various forms) is now actually just a spellout of agreement features on the null copular Pred head in the present tense. In essence, a Hebrew example with the pronominal is just like a Scottish Gaelic example with the defective copula. This captures the interpretational similarities between the two constructions.

What of the apparent equative sentences? The system we have developed predicts that there is a null pro predicate in the structure in these cases, perhaps related to Hebrew's pro-drop status. Our hypothesis is that the null present tense true copula (that is, the non-eventive Pred head) is an obligatorily agreeing form, while the null present tense substantive auxiliary (which simply satisfies requirements of T) is not.

The cases in Hebrew where the agreement is optional are all cases where the predication can be constructed using either a situational variable or a simple individual variable as the subject of the predication. Recall that in Scottish Gaelic, predication using adjectives and predicative nominals could be formed using both the ICC and substantive SAC construction types. The following examples from Greenberg (1997) make clear the difference in interpretation. In (119), with the pronominal form, we are unambiguously ascribing the property of blueness to the sky, where the latter is conceived of as a spatio-temporally unbounded individual; while in (120), without a pronoun, the statement is about the present situation, where the sky happens to be blue.

(119) ha-Samayim hem kxulim

the sky pron-3MPL blue

'The sky is blue (in general, by its nature).'

(120) ha-Samayim kxulim.

the sky blue

'The sky is blue (now, today).' 
The analysis we have proposed for Scottish Gaelic therefore has the striking property that it can unify the contexts in which the $h u$ form appears in Hebrew-a unity absent from previous accounts of the phenomenon. It also offers a natural reason for why it is the pronominal form $h u$ that has ended up being the etymological source of predicate agreement in copular contexts.

\subsection{English}

The hypothesis we have been defending in this paper is that predicational constructions all reduce to the same syntactic/semantic type: there is a Pred head which takes a property as its complement. the Pred head may either be eventive or non-eventive, but its basic function is the same in either case. The selectional requirements of the Pred head are always for a property denoting complement. It follows from the strongest version of this hypothesis, that no language should have a pred head which takes a complement of SDP type. This means that Pred can never encode an identity predicate.

This naturally raises a question for English, where it has been argued by various researchers, either that the verb be itself is ambiguously an identity predicate (Higginbotham 1987), or that one of the small clause types in English involves an identity predicational head (Heycock and Kroch 1999).

The first obvious difference between English and Scottish Gaelic, is that, in the former language, nominals headed by many determiners (e.g. the and $a$ ) can also appear in predicative contexts. The evidence from small clause complements of a verb like consider shows that there are environments which demonstrate a clear predicational asymmetry between the two nominals. Thus, in examples like (121a,b) below, these can appear in subject position but not in predicate position of the small clause.

(121) (a) I consider [these the best pictures of Mary].

(b) * I consider [the best pictures of Mary these].

Under the approach taken so far in this paper, this is expected. Following Zamparelli, we take determiners in English to be generated lower down in the structure than SD. Zamparelli provides arguments that English determiners may be generated in PDP. In this sense, they contrast with determiners in Scottish Gaelic, which are obligatorily generated in SD.

Given this difference, we propose that the English determiners themselves are instantiations of Pred heads. In an example like (121a), the determiner the is the head of PredP, and the demonstrative these is its specifier. The ungrammatical (121b) is predicted by the fact that the demonstrative is obligatorily generated in $\mathrm{SD}$, so there is no preceding position for the subject of a predication. However, the crucial challenge to this simple picture comes from the contrast between the examples above and the constructions using the verb be as in $(122 \mathrm{a}, \mathrm{b})$ below, where no asymmetry is found.

(122) (a) I consider these to be the best pictures of Mary.

(b) The consider the best pictures of Mary to be these.

If we assume that the verb be in English is, optionally, the identity predicate, or alternatively, that English possesses a null predicational head with identity semantics that can be selected by this auxiliary verb, then these data receive a straightforward explanation. However, this weakens the force of our discussion in general.

The contrast also receives an explanation within the system of Moro (1997), who posits that the predicate, rather than the subject, may raise to the specifier of TP (see the discussion in section (3.1)). In this framework, the verb be provides extra functional material in the clause to which either of the two DPs in the lower predicational structure may raise, giving rise to an apparently inverted structure. Such functional material is missing in the complement of a consider-type verb. 
While this latter account is more consistent with the general approach taken in this paper, it faces the problem of how to constrain and motivate the operation of predicate-raising in sentences using $b e$. The facts are that only nominals (and not AP, PP or verbal projections) may undergo predicate raising. Furthermore, it appears that only identificational meanings are possible in the inverted sentence type. Consider sentences (123) and (124) below.

(123) (a) I consider what you are talking about to be garbage.

(b) What you are talking about is garbage.

(124) I consider garbage to be what you are talking about.

(b) Garbage is what you are talking about.

While (123a,b) are ambiguous between an identificational and a specificational meaning (Higgins 1973), $(124 a, b)$ can only have an identificational interpretation. In other words, predicate raising of garbage cannot be the method by which (124) is derived, unless predicate raising is restricted to small clauses with a particular kind of meaning. It seems that once again we are forced into assuming a null predicational head with identity semantics.

We would like to offer a slightly different account of these data, still along the lines of Moro (1997), which maintains the strongest hypothesis we have been entertaining so far (that there is only one kind of predicational structure mediated by a Pred head). This account relates the existence of identificational readings to the verb be in English, and, in some ways, goes back to the spirit of the type-shifting framework of Partee (1987). We assume as before that SDPs must be arguments and that only PredPs are predicates; English nominals headed by the can be of either type, but some, like these or what I am talking about can only be SDPs. This explains the small clause data in (125) and (126).

(125) *I consider garbage what you are talking about.

(126) I consider what you are talking about garbage.

The verb be represents extra lexical material — a verbal head which can select either property denoting projections (APs, PPs or KIPs), or referential SDPs. In this respect, it is unlike the Pred head, which is part of an extended projection and which can only combine with properties. Be is a lexical head which combines with anything of an atomic type (either $\pi$ or e) to create a derived property (127). This derived property can then be selected by the null Pred head.

(127) $\lambda x[\iota \pi$ : where $\pi$ is the property relevantly associated with $\mathrm{x}]$

19

If the verb be can combine with either KIPs or SDPs to create something uniformly of type $<\mathrm{e}, \mathrm{t}\rangle$, then this explains why (123) is ambigous in English: garbage can either be a KIP or an SDP and will give rise to slightly different predicates in each case; while what I am talking about which is in subject position will be an unambiguous SDP. We assume, in addition, that English allows the raising of a projection to satisfy the EPP feature of T. However, we stipulate that the projection so raised must be an SDP. Technically, we assume that SDPs are the only potentially Case bearing projections, and that only these are of the right syntactic category to bear the syntactic feature that will satisfy EPP in English. ${ }^{20}$ This means that only in

\footnotetext{
${ }^{19}$ The semantics of the property constructed is left deliberately vague and contextual, since properties constructed using the verb $b e$ in English are notoriously variable.

${ }^{20}$ This remains a stipulation in our account at the moment, but it might find a deeper explanation in generalisations concerning the semantic partition of syntactic structure à la (Diesing 1992).
} 
cases where 'be' has selected an SDP as its complement, will the projection embedded inside the PredP be able to raise to give an inverted structure. This explains the lack of ambiguity in (124): only the SDP version of 'garbage' as the complement of 'be' is a possible source for the inversion structure here. Consider again the situation in (128) below in English.

\section{(128) Hamlet is Sean tonight.}

Even though 'Hamlet' is an SDP, it is still interpreted as a role here, because it has been selected as the complement of 'be'. It is in subject position because it has raised to satisfy the EPP feature of T.

The strongly symmetrical equatives such as (129) also have an account in this system.

\section{(129) Cicero is Tully.}

We argue that there are two possible derivations for this sentence. Under the first, 'Tully' is the complement of 'be' and gives rise to the derived property 'the property of referring to Tully'. This property is then predicated straightforwardly of the SDP 'Cicero' which raises to satisfy the EPP property of T. The other derivation involves 'Cicero' being selected as the complement of 'be', giving rise to the derived property 'the property of referring to Cicero'". 'Cicero' is then raised to satisfy the EPP feature of T. Thus, in either case there is always a predicational asymmetry, depending on whether the speaker wishes to convey new information about the name 'Tully' or about the name 'Cicero'. We believe that the asymmetry of predication is difficult to detect in the sentence above because of the subtlety of the difference in interpretation and because both readings are actually possible because of inversion.

There are thus two crucial differences between English and Scottish Gaelic: (i) in Scottish Gaelic the copula really is the Pred head, and is constrained to combining with only property denoting projections, and (ii) the EPP in English is satisfied only by SDPs, whereas in Scottish Gaelic it is the predicative head that must raise (pied-piping extra material in the case of the copula).

Of course, this account rests on a basic stipulation about the (perhaps unorthodox) meaning given to the verb be in English, and the stipulation that only SDPs may raise in English to satisfy the EPP. However, given that some language-specific stipulation seems to be an irreducible consequence of this data, we believe that it is a natural one to assume. The point of this section has been to show that it is possible to give an account of the English data which eschews the use of an identity predicational functional head.

\section{Conclusion}

Scottish Gaelic seems to show evidence of a number of strikingly different types of predicational structure, especially when it comes to nominal predication. We have shown in this paper that all of those construction types actually conform to one simple syntactic predicational structure, correlated with one set of semantic relationships. Thus, despite the initial appearances of a particularly knotty counterexample to the claim that there is really only one kind of predicational syntax, Scottish Gaelic ends up confirming the most restrictive hypothesis concerning the nature of predication in natural language.

In addition, we have examined some classic cases in the literature of languages which construct identity predications in radically different ways: (i) Polish, which uses morphological case in addition to a pronominal augment; (ii) Hebrew, a language in which the pronominal element is either obligatory or optional; and (iii) English, which uses neither pronouns nor casemarking and seems to offer evidence for a null identificational predicate. We have shown that the approach taken for Scottish Gaelic can plausibly be extended to account for these superficially different language systems as well. We take this as initial but tantalizing support for the idea that the restrictive hypothesis concerning the syntax and semantics of predication that we have been defending may be on the right track. 


\section{References}

Adger, David. 1996. Agreement, aspect and measure phrases in Scottish Gaelic. In Robert Borsley and Ian Roberts, eds., The Syntax of the Celtic Languages, Cambridge: Cambridge University Press.

Adger, David. 1999. Predication and comparison in Scottish Gaelic, paper presented at the Third Celtic Linguistics Conference, Dublin.

Adger, David. 2000. VSO clause structure and morphological feature checking. In Robert Borsley, ed., Syntactic Categories, New York: Academic Press.

Adger, David. 2001. A predicational head in Scottish Gaelic, ms. University of York.

Alexiadou, Artemis and Anagnostopoulou, Elena. 1998. Parameterizing AGR. Natural Language and Linguistic Theory 16:491-539.

Bowers, John. 1993. The syntax of predication. Linguistic Inquiry 24:591-656.

Cardinaletti, Anna. 1993. On the internal structure of pronominal DPs. Technical Report 3, University of Venice Working Papers in Linguistics.

Carlson, Greg. 1977. Reference to kinds in English. Ph.D. thesis, University of Massachusetts at Amherst.

Carnie, Andrew. 1995. Non-verbal predication and head movement. Ph.D. thesis, Massachusetts Institute of Technology.

Carnie, Andrew. 1997. Two types of non-verbal predication in Modern Irish. Canadian Journal of Linguistics 42:57-73.

Chierchia, Gennaro. 1984. Topics in the syntax and semantics of infinitives and gerunds. Ph.D. thesis, University of Massachusetts at Amherst.

Chomsky, Noam. 1995a. Bare phrase structure. In Gert Webelhuth, ed., Government and Binding theory and the Minimalist Program, 383-439, Cambridge, MA: Basil Blackwell.

Chomsky, Noam. 1995b. The Minimalist Program. Cambridge, MA: MIT Press.

Chomsky, Noam. 1998. Minimalist Inquiries. MITOPL 15.

Chomsky, Noam. 1999. Derivation by Phase. MITOPL 18.

Chung, Sandra and McCloskey, James. 1987. Government, barriers and small clauses in Modern Irish. Linguistic Inquiry 18:173-237.

Cottell, Siobhán. 1997. Focus and clefts in Modern Irish. Proceedings of CONSOLE 6.

Diesing, M. 1992. Indefinites. Cambridge, MA: MIT Press.

Doherty, Cathal. 1996. Clausal structure and the Modern Irish copula. Natural Language and Linguistic Theory 14:1-46.

Doherty, Cathal. 1997. Predicate initial constructions in Irish. In Brian Agbayani and Sze-Wing Tang, eds., Proceedings of West Coast Conference on Formal Linguistics (WCCFL) 15, 81-95, Stanford: CSLI Publications.

Doron, Edit. 1983. Verbless predicates in Hebrew. Ph.D. thesis, University of Texas at Austin.

Doron, Edit. 1988. The semantics of predicate nominals. Linguistics 26:281-301.

Eid, M. 1983. The copula function of pronouns. Lingua 59:197-207.

Greenberg, Yael. 1997. Hebrew nominal sentences and the generic/non-generic distinction, ms. BarIlan University. 
Greenberg, Yael. 1998. An overt syntactic marker for genericity in Hebrew. In Susan Rothstein, ed., Events and Grammar, 125-143, Dordrecht: Kluwer.

Hale, Ken and McCloskey, James. 1984. On the syntax of person-number inflection in Modern Irish. Natural Language and Linguistic Theory 1:487-533.

Heggie, Lorie H. 1988. The syntax of copular structures. Ph.D. thesis, University of Southern California.

Heim, Irene. 1982. The semantics of definite and indefinite noun phrases. Ph.D. thesis, University of Massachusetts at Amherst.

Heycock, Caroline. 1994. The internal structure of small clauses. In Proceedings of the North Eastern Linguistics Society (NELS) 25, volume 1, 223-238.

Heycock, Caroline and Kroch, Anthony. 1999. Pseudocleft connectedness: implications for the LF interface level. Linguistic Inquiry 30:365-398.

Higginbotham, James. 1985. On semantics. Linguistic Inquiry 16:547-593.

Higginbotham, James. 1987. Indefiniteness and predication. In Eric Reuland and Alice ter Meulen, eds., The representation of (in)definiteness, 43-70, Cambridge, MA: MIT Press.

Higgins, Roger. 1973. The Pseudo-Cleft construction in English. New York: Garland.

Hoekstra, Teun. 1984. Transitivity: Grammatical Relations in Government and Binding Theory. Dordrecht: Foris.

Hornstein, Norbert and Lightfoot, David. 1987. Predication and PRO. Language 63:23-52.

Jelinek, Eloise. 1984. Empty categories, case and configurationality. Natural Language and Linguistic Theory 2:39-76.

Kratzer, Angelika. 1995. Stage and individual level predicates. In Greg N. Carlson and Francois J. Pelletier, eds., The Generic Book, Chicago, IL: University of Chicago Press.

Krifka, Manfred et al. 1995. Genericity: An introduction. In Greg N. Carlson and Francois J. Pelletier, eds., The Generic Book, 1-124, Chicago, IL: University of Chicago Press.

Larson, Richard. 1987. On the double object construction. Linguistic Inquiry 19:589-632.

Lee, Felicia. 1999. Cleft constructions in Zapotec: Evidence for pronominal predicates. In Patrick Sauzet, ed., Proceedings of the Third Langues et Grammaire, 131-145, Departement des Sciences du Language.

Longobardi, Giuseppe. 1994. Proper names and the theory of N-movement in syntax and logical form. Linguistic Inquiry 25:609-665.

Manzini, Rita. 1983. Restructuring and reanalysis. Ph.D. thesis, MIT.

McCloskey, James. 1983. A VP in a VSO language? In Gerald Gazdar, Ewan Klein, and Geoff Pullum, eds., Order Concord and Constituency, 9-55, Dordrecht: Foris.

Moro, Andrea. 1988. Per una teoria unificata delle frasi copulari. Rivista di Grammatica Generativa 13:81-110.

Moro, Andrea. 1997. The Raising of Predicates. Cambridge: Cambridge University Press.

Parsons, Terrence. 1990. Events in the Semantics of English. Cambridge, MA.: MIT Press.

Partee, Barbara Hall. 1987. Noun phrase interpretation and type-shifting principles. In J. A. G. Groenendijk et al., ed., Studies in discourse representation theory and the theory of generalized quantifiers, 115-143, Dordrecht: Foris. 
Pereltsvaig, Asya. 2001. On the nature of intra-clausal relations: a study of copular sentences in Russian and Italian. Ph.D. thesis, McGill University, Montréal.

Pesetsky, David and Torrego, Esther. 2000. T to C movement: causes and consequences, ms., MIT, Cambridge, MA.

Ramchand, Gillian. 1996. Two types of predication in Scottish Gaelic. Natural Language Semantics 4:165-191.

Ramchand, Gillian. 1997. Aspect and Predication:The Semantics of Argument Structure. Oxford: Oxford University Press.

Rapoport, Tova. 1987. Copular, nominal and small clauses: A study of Israeli Hebrew. Ph.D. thesis, MIT.

Raposo, Eduardo and Uriagereka, Juan. 1990. Long-distance case assignment. Linguistic Inquiry 21:505-537.

Rothstein, Robert A. 1986. Equation vs. ascription: the nominative/instrumental opposition in West Slavic. In Richard Brecht and James S. Levine, eds., Case in Slavic, Columbus, Ohio: Slavica Publishers.

Rothstein, Susan. 1995. Small clauses and copular constructions. In Anna Cardinaletti and MariaTeresa Guasti, eds., Small Clauses, 27-48, New York: Academic Press.

Rouveret, Alain. 1996. Bod in the present tense and in other tenses. In Robert Borsley and Ian Roberts, eds., The Syntax of the Celtic Languages, 125-170, Cambridge: Cambridge University Press.

Stenson, Nancy. 1977. Overlapping systems in the Irish comparative construction. Word 28.

Stenson, Nancy. 1981. Studies in Irish Syntax. Tuebingen: Gunter Narr.

Stowell, Tim. 1981. Origins of phrase structure. Ph.D. thesis, MIT, Cambridge, MA.

Svenonius, Peter. 1994. Dependent nexus: Subordinate predication structures in English and the Scandinavian Languages. Ph.D. thesis, UCSC, Santa Cruz, CA.

Williams, Edwin. 1980. Predication. Linguistic Inquiry 11:203-237.

Williams, Edwin. 1983a. Against Small Clauses. Linguistic Inquiry 14:287-308.

Williams, Edwin. 1983b. Semantic vs. syntactic categories. Linguistics and Philosophy 6:423-446.

Williams, Edwin. 1994. Thematic Structure in Syntax. Cambridge, MA.: MIT Press.

Zamparelli, Roberto. 2000. Layers in the Determiner Phrase. New York: Garland.

Zaring, Laurie. 1996. Two "be" or not two "be": Identity, predication and the Welsh copula. Linguistics and Philosophy 19:103-142.

Authors:

David Adger

Dept of Linguistics

University of York

Heslington York YO1 5DD

da4@york.ac.uk
Gillian Ramchand

Centre for Linguistics and Philology

University of Oxford

Walton Street, Oxford OX12HG

gcram@ermine.ox.ac.uk 